\title{
Therapeutic Role of Beta-blockers in Hypertension: A Pragmatic Reappraisal
}

\section{Soumitra Kumar}

\begin{abstract}
Beta-blockers have been used as first-time antihypertensives for decades and such use has also been recommended by guidelines. However, subsequently some meta-analyses questioned this status of beta-blockers by bringing to light their limitation in terms of stroke prevention and their metabolic sideeffects. Following this, several major international hypertension guidelines have removed beta-blockers from the first line of recommended drugs. Some other guidelines, however, have retained them as first-line antihypertensive. Age is an important determinant of choice of antihypertensives and beta-blockers have proven to be very useful in young hypertensives especially if overweight. Amidst these controversies, vasodilatory beta-blockers have emerged with a new promise. They are potent antihypertensives with better reduction of central aortic pressure and a neutral or favorable metabolic profile.
\end{abstract}

Keywords: Age, Metabolic effects, Stroke, Vasodilatory.

How to cite this article: Kumar S. Therapeutic Role of Betablockers in Hypertension: A Pragmatic Reappraisal. Hypertens J 2016;2(2):80-85.

Source of support: Nil

Conflict of interest: None

\section{INTRODUCTION}

The concept of adrenergic blockade can be traced to the work of Ahlquist ${ }^{1}$ when he described two discrete types of adrenergic receptors, classified as alpha and beta receptors. Later, James Black ${ }^{2}$ in his work reported two non-selective beta-blockers pronethalol, with an endogenous sympathomimetic action, and propranolol, without such action for which he received the Nobel Prize for Medicine and Physiology in 1988. Pronethalol was discarded as carcinogenic but propranolol went on to become standard therapy for angina and arrhythmias. Later, propranolol became accepted as an oral antihypertensive medication. In 1967, Lands et $\mathrm{al}^{3}$ described two types of beta-receptors, beta $_{1}$ and beta 2 . Practolol was described as the first beta - $_{1}$ selective blocker in 1970, but after

\section{Professor and Head}

Department of Cardiology, Vivekananda Institute of Medical Sciences, Kolkata, West Bengal, India

Corresponding Author: Soumitra Kumar, Professor and Head, Department of Cardiology, Vivekananda Institute of Medical Sciences, Kolkata, West Bengal, India, Phone: +919831032519, e-mail: dr.soumitrakumar@gmail.com
4 years of clinical use, ${ }^{4}$ it was abandoned on grounds of severe toxicity. In the following years, more non-selective beta-blockers (nadolol, timolol), beta ${ }_{1}$-selective blockers (atenolol, metoprolol, betaxolol, bisoprolol), beta-blockers with an endogenous sympathomimetic action (pindolol, oxprenolol, caliprolol), and alpha/beta blocker (labetalol) emerged.

In more recent years, newer beta-blockers with vasodilatory properties, such as carvedilol and nebivolol, have emerged. Carvedilol is a non-selective adrenergic blocker with both alpha $a_{1}$ and beta $a_{1,2}$ receptor-blocking actions and a consequent direct vasodilatory effect. ${ }^{5}$ Nebivolol is a beta-blocker with high selectivity for beta ${ }_{1}$ receptors but without any intrinsic sympathomimetic action. ${ }^{6}$ It has an unique property of promoting endothelial production of nitric oxide $(\mathrm{NO})$, thus causing vasodilation. The newer vasodilatory beta-blockers have the promise to provide several pleiotropic benefits beyond blood pressure control.

Following the introduction of propranolol in 1976, beta-blockers have been widely used for the treatment of systemic hypertension for around 40 years. However, some recent meta-analyses have suggested that they are significantly inferior to other classes of antihypertensives [thiazide diuretics, calcium channel blockers, angiotensinconverting enzyme (ACE) inhibitors, angiotensin-II receptor blocker]. Based on this, some international hypertension guidelines have demoted beta-blockers to the fourth-line amongst antihypertensive drugs. The clinical trials and meta-analyses which have had an effect on such clinical practice guidelines are reviewed below.

\section{CLINICAL TRIALS OF BETA-BLOCKERS IN HYPERTENSION}

The major clinical studies which have been included in most of the meta-analyses on use of beta-blockers are as follows:

- One trial with propranolol (MRC: Medical Research Council trial)

- One trial with oxprenolol (IPPSH: International Prospective Primary Prevention Study in Hypertensives)

- Two trials with pindolol (STOP-Hypertension: Swedish Trial in Old Patients with Hypertension and STOP-2: Swedish Trial in Old Patients with Hypertension-2)

- Six trials with metoprolol (HAPPHY: Heart Attack Primary Prevention in Hypertension; MAPHY: 
Metoprolol Atherosclerosis Prevention in Hypertensives; STOP-Hypertension; STOP-2; CAPP: Captopril Primary Prevention Project; AASK: African American Study of Kidney Disease and Hypertension)

- Thirteen trials with atenolol (HEP: Hypertension in Elderly Patients with Primary care; HAPPHY; STOPHypertension; STOP-2; MRC; CAPP; UKPDS: UK Prospective Diabetes Study; AASK; ELSA: European Lacidipine on Atherosclerosis; LIFE: Losartan Intervention for Endpoint Reduction in Hypertension; INVEST: International Verapamil Trandolapril Study; CONVINCE: Controlled Onset Verapamil Investigation of Cardiovascular End Points; ASCOTBPLA: Anglo-Scandinavian Cardiac Outcomes Trial Blood Pressure Lowering Arm)

No trials till date have been carried out with vasodilating beta-blockers in hypertension.

Some of the more noteworthy trials are discussed below:

In the HAPPHY trial, ${ }^{7}$ diuretics (bendrofluazide or hydrochlorothiazide) have been compared with betablockers (metoprolol or atenolol) in 6,569 patients aged from 40 to 64 years for coronary events and deaths. There were no significant differences in the endpoints between the two groups of drugs. The MAPHY trial ${ }^{8}$ was a follow-up extension of HAPPHY trial. The followup median time was 4.2 years, and the results indicated a lower total and cardiovascular mortality in the group taking beta-blockers.

In the UKPDS trial, ${ }^{9} 1,148$ hypertensive patients with type 2 diabetes mellitus were allocated to a tight control of $\mathrm{BP}$ using either captopril or atenolol. In this small sample size, both treatments were equally effective in reducing $\mathrm{BP}$ and also equally effective in reducing macrovascular endpoints, deaths, myocardial infarction (MI), and stroke.

In the INVEST trial, ${ }^{10}$ the largest trial that investigated beta-blockers, 22,576 patients with hypertension and coronary artery disease were randomized to a calcium antagonist strategy or atenolol. Trandolapril and/or hydrochlorothiazide were added to reach the target $\mathrm{BP}$ of 140/90 or 130/85 (for diabetic subjects). The atenololbased strategy was as effective as the calcium channel blocker-based strategy for preventing cardiac events and stroke.

In the LIFE trial, ${ }^{11}$ 9,193 patients with hypertension and left ventricular hypertrophy and average age of 66 years were randomized to an atenolol-based strategy or a losartan-based strategy. Despite similar BP reduction, there was a greater reduction in cardiovascular endpoints (MI, stroke, and death) in the group taking losartan.

In the CONVINCE trial, ${ }^{12} 16,602$ hypertensive patients were randomized either to controlled-release verapamil or to either hydrochlorothiazide or atenolol. Effectiveness of the calcium channel blocker in reducing cardiovascular disease was similar but not better than a diuretic or betablocker-based treatment.

In the ASCOT-BPLA trial, ${ }^{13}$ an antihypertensive regimen based on amlodipine with perindopril was compared to a regimen based on atenolol with bendroflumethazide and potassium as required. There was a statistically significant lowering in fatal and nonfatal strokes, total cardiovascular events and procedures, and all cause mortality in the amlodipine-perindopril group.

The Conduit Artery Function Evaluation (CAFÉ) substudy ${ }^{14}$ of ASCOT-BPLA trial assessed central aortic pressure indirectly and amlodipine-based strategy was associated with lower central BP compared with atenololbased therapy group.

\section{META-ANALYSES OF STUDIES WITH BETA-BLOCKERS}

Messereli et $\mathrm{al}^{15}$ conducted the first meta-analysis of studies in 1998 comparing the use of beta-blockers with diuretics in an elderly ( $\geq 60$ years of age) hypertensive population $(8,217$ patients). Both treatment groups reduced cerebrovascular events but beta-blockers did not reduce coronary events or mortality. Overall conclusion was that beta-blockers should not be used as first-line therapy in elderly patients any longer.

In 2001, a much larger meta-analysis comprising 62,605 patients conducted by Staessen et $\mathrm{al}^{16}$ included diuretics, beta-blockers, calcium channel blockers, and ACE inhibitors. All agents had similar long-term efficacy and safety, but the results of beta-blockers and diuretics were analyzed together.

Lindholm et $\mathrm{al}^{17}$ reported a larger meta-analysis of 13 trials that compared beta-blockers with other treatments (105,951 subjects) and 7 trials that compared beta-blockers with placebo or no treatment in 27,433 patients. In the first arm, there was an increased risk of stroke with betablockers compared with other antihypertensive agents. Beta-blockers (predominantly atenolol) reduced the risk of stroke in the placebo-controlled trials but only by $50 \%$ of what was expected with other agents. No trial compared the use of atenolol with other beta-blockers.

Law et $\mathrm{l}^{18}$ conducted the largest meta-analysis comparing different classes of BP lowering drugs in 464,000 patients. According to this analysis, five main classes of antihypertensive agents (thiazide, calcium channel blockers, beta-blockers, angiotensin receptor blockers, and ACE inhibitors) showed similar efficacy within a few percentage points in preventing coronary heart disease and stroke.

Most recent meta-analysis is an update by Kuyper and $\mathrm{Khan}^{19}$ of a previous meta-analysis by Khan and McAlister. ${ }^{20}$ Conclusion of a large meta-analysis 
comprising 145,811 participants from 21 hypertension trials concluded that the use of beta-blockers in younger patients is advisable since it is associated with significant reduction in cardiovascular morbidity and mortality but they should not be considered first-line therapy in older patients. The updated meta-analysis was unique in the sense that the authors sought to compare efficacy of atenolol vs non-atenolol beta-blockers and also stratified patients according to age. They concluded that both atenolol and non-atenolol beta-blockers decrease cardiovascular endpoints in young patients, suggesting that age is a more important factor in the selection of antihypertensive, and type of beta-blocker chosen may be less important. The authors also concluded that whether significantly worse outcome in older hypertensives is a class effect of beta-blockers or specific to atenolol remains unclear. Whether lack of lowering of central BP in elderly population as reported by CAFE study ${ }^{14}$ can be attributed as an explanation remains a hypothesis. The possibility that metabolic effects of non-vasodilating beta-blockers may also be responsible has been suggested by the authors, but hard outcomes studies are required to prove this.

\section{USE OF BETA-BLOCKERS IN COMPELLING INDICATIONS}

Coronary artery disease: Beta-blockers are recommended by several guidelines for use in hypertensive patients with coronary artery disease because they reduce blood pressure, heart rate, and myocardial oxygen demand; as a consequence, they reduce ischemia. ${ }^{21,22}$ Effects of nonvasodilating beta-blockers on coronary blood flow are variable. Vasodilatory beta-blockers have the potential to improve coronary blood flow at rest and also during exercise so that they can be a better option than traditional beta-blockers; however, currently vasodilating betablockers are not recommended by use in chronic stable angina.

Postmyocardial infarction: Valuable role of beta-blockers in patients after MI has been established by several trials (BHAT, the Gothenburg Metoprolol trial, the Norwegian Timolol trial, CAPRICORN) ${ }^{23-26}$ and accordingly it is compelling to use beta-blockers in hypertensive patients following MI. ${ }^{21,22}$

Heart failure: Several meta-analyses of beta-blocker trials have conclusively established that beta-blocker use results in a consistent $30 \%$ reduction in mortality, $40 \%$ reduction in hospitalization, and 38\% reduction in sudden cardiac death in patients with chronic heart failure. ${ }^{27,28}$ Another meta-analysis reported that 26 patients would need to be treated to avoid one death..$^{29}$ Bisoprolol, metoprolol succinate, and carvedilol are approved for use in hypertensive patients with chronic systolic heart failure. In the SENIORS trial, nebivolol was shown to reduce the composite risk of all-cause mortality or cardiovascularrelated hospital admission by $14 \%$ compared to placebo $(p=0.039)$, but not all-cause mortality alone. ${ }^{30}$ It is not currently approved for use in heart failure indication.

\section{AGE AND CHOICE OF BETA-BLOCKERS AS ANTIHYPERTENSIVES}

The Framingham Heart Study showed that in younger subjects, diastolic blood pressure was the prime predictor of cardiovascular events, shifting to systolic blood pressure and then pulse-pressure with increasing age. ${ }^{31}$ This effect was particularly evident in overweight/obese subjects. ${ }^{32}$ Such young subjects have a high adrenergic drive and cardiac output, and first-line beta-blockade has performed well in such patients, both in terms of controlling blood pressure and in preventing MI. ${ }^{33-35} \mathrm{In}$ comparison, first-line beta-blockade (mainly atenolol) has performed poorly in reducing cardiovascular risk in elderly hypertensives. Reasons may be attributed to metabolic disturbances that may be evoked, lack of improvement of vascular compliance, or lack of effect on central aortic pressure, or poor reversal of left ventricular hypertrophy. Beta-blocker-induced bradycardia may not work beneficially in all hypertensive patients. This paradox has to do with the reflected pulse wave. Ideally the reflected wave that should reach the heart is diastole and augment diastolic filling. If it returns earlier during the cardiac cycle it amplifies the outgoing pressure wave, i.e., worsens augmentation index and raises central aortic pressure. This phenomenon especially results from the combination of beta-blocker-induced bradycardia in elderly patients with "stiff" arteries and it is termed "pseudo-antihypertensive effect." ${ }^{\text {"36 }}$ However, not all pharmacological effects of beta-blockers in the elderly are undesirable. Elderly patients, unlike their younger counterparts, experience a decreased pulsepressure on standing. This effect is offset and turned into a "paradoxic" pressor effect by long-term betablocker treatment and this may protect the elderly from orthostatic symptoms. ${ }^{37}$

\section{ARE VASODILATING BETA-BLOCKERS DIFFERENT?}

Vasodilatory beta-blockers by causing peripheral vasodilation reduce cardiac preload and afterload. Thus, they reduce blood pressure by reducing systemic vascular resistance while maintaining cardiac output. ${ }^{38,39}$ Vasodilatory beta-blockers are also devoid of any adverse effect on lipid and glucose metabolism and they can 
reverse arterial remodeling. Remodeled (Stiff) arteries increase distal wave reflection of blood back to the aorta, which augment central systolic pulse wave emanating from the heart to increase central aortic pressure. Thus, vasodilatory beta-blockers have the potential to lower central aortic pressure. ${ }^{38}$

Vasodilatory beta-blockers that are currently in clinical use are labetalol, carvedilol, and nebivolol. Labetalol and carvedilol are non-selective beta-blockers

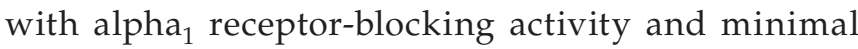
(labetalol) or no (carvedilol) intrinsic sympathomimetic activity. ${ }^{38,39}$ Nebivolol is a high beta ${ }_{1}$-selective blocker that does not have alpha $\mathrm{a}_{1}$-blocking activity or intrinsic sympathomimetic activity. ${ }^{38,39}$ Nebivolol mediates endothelium-dependent vasodilatation via the L-arginine-nitric oxide (NO)-dependent pathway. The combination of beta-adrenoceptor antagonism and NO-mediated vasodilatation not only potentiates the blood pressure activity of nebivolol but also confers a broader and favorable metabolic profile. ${ }^{40}$ Nebivolol not only significantly reduces central aortic pressure along with brachial pressure but also significantly reduces augmentation index and carotid-femoral pulse wave velocity, both being independent cardiovascular risk markers. ${ }^{41}$ In terms of control of blood pressure, a meta-analysis of 12 randomized clinical trials in patients with hypertension has shown that nebivolol was superior to ACE inhibitors and comparable to other beta-blockers, calcium channel blockers, and losartan. ${ }^{42}$

\section{WHAT IS THE CURRENT ROLE OF BETA- BLOCKERS IN TREATING HYPERTENSION?}

Despite exclusion of beta-blockers as first-line drugs in some leading international guidelines of hypertension, ${ }^{43-45}$ some other guidelines like European and Canadian Hypertension Guidelines have retained beta-blockers as one of the five first-line antihypertensive drugs. ${ }^{46,47}$ Major reasons accounting for relegation of beta-blockers from first line are their failure to reduce stroke incidence and their adverse metabolic profile, especially causation of new-onset diabetes mellitus. However, guidelines that have retained them rate beta-blockers very effective in young hypertensives, especially in overweight individuals. All guidelines, however, express concurrence in terms of indispensability of beta-blockers in some compelling indications like hypertension in patients suffering from angina, heart failure, and post-MI.

Amidst the controversy involving beta-blockers, in recent times, vasodilatory beta-blockers have emerged with a new promise. Whereas, they lower blood pressure to a similar degree as other antihypertensive drugs, they may provide better central aortic pressure reductions compared to traditional beta-blockers and are also associated with neutral or favorable metabolic effects. There is, however, lack of data comparing hard cardiovascular outcomes between vasodilating and nonvasodilating beta-blockers in hypertension.

It is unlikely that there will be a single first-line drug for hypertensives as most patients will eventually need multiple drugs to control their blood pressure. Treatment needs to be individualized for all patients. Chronic regular use of beta-blockers has been associated with detrimental effects including an increase in asthmarelated deaths. However, more recent data ${ }^{48}$ suggest that certain beta-blockers, specifically beta-adrenoceptor inverse agonists (e.g., nadolol), may be useful in chronic treatment of asthma by inhibiting constitutive or ligandinduced activation of this pathway. Choice of treatment should not only be dictated by underlying cardiovascular risk factors and potential adverse effects, but also by the age of the patient and his/her co-morbidities. In that scenario, beta-blockers, especially its newer vasodilatory versions, will continue to be an integral part of our antihypertensive regime.

\section{REFERENCES}

1. Ahlquist RP. A study of adrenergic receptors. Am J Physiol 1948;153(3):586-599.

2. Black JW, Growther AF, Shanks RG. A new adrenergic betareceptor antagonist. Lancet 1964 May 16;1(7342):1080-1081.

3. Lands AM, Arnold A, McAuliff JP. Differentiation of receptor systems activated by sympathomimetic amines. Nature 1967 May 6;214(5088):597-598.

4. Wright P. Untoward effect associated with practolol administration: oculomucocutaneous syndrome. BMJ 1975 Mar 15;1(5958):595-598.

5. Frishman WH. Carvedilol. N Engl J Med 1998 Dec 10;339(24): 1759-1765.

6. Tzemos N, Lim PO, MacDonald TM. Nebivolol reverses endothelial dysfunction in essential hypertension. A randomized, double-blind, cross-over study. Circulation 2001 Jul 31;104(5):511-514.

7. Wilhelmsen L, Berglund G, Elmfeldt D, Fitzsimons T, Holzgreve H, Hosie J, Hörnkvist PE, Pennert K, Tuomilehto J, Wedel H. Beta-blockers versus diuretics in hypertensive men: main results from the HAPPHY Trial. J Hypertens 1987 Oct;5(5):561-572.

8. Wikstrand J, Warnold J, Olsson G, Tuomilehto J, Elmfeldt D, Berglund G. Primary prevention with metoprolol in patients with hypertension. JAMA 1988 Apr;259(13):1976-1982.

9. Stearne MR, Palmer SL, Hammersley MS, Franklin SL, Spivey RS, Levy JC, Tidy CR. Efficacy of atenolol and captopril in reducing risk of macrovascular and microvascular complications in type 2 diabetes. UKPDS 39, UK Prospective Diabetes Study Group. Brit Med J 1998 Sep 12;317(7160): 713-720.

10. Pepine CJ, Handberg EM, Cooper-Del Hoff RM. A calcium antagonist $v s$ a non-calcium antagonist hypertension treatment strategy for patients with coronary disease. The 
International Verapamil-Trandolapril Study (INVEST): a randomized controlled trial. JAMA 2003 Dec 3;290(21): 2805-2816.

11. Dalhof B, Devereux RB, Kjeldsen SE, Julius S, Beevers G, de Faire U, Fyhrquist F, Ibsen H, Kristiansson K, LederballePedersen $\mathrm{O}$, et al. Cardiovascular morbidity and mortality in the Losartan Intervention for Endpoint reduction in hypertension study (LIFE): a randomized trial against atenolol. Lancet 2002 Mar 23;359(9311):995-1003.

12. Black HR, Elliott WJ, Grandits G. Principal results of the Controlled Onset Verapamil Investigation of cardiovascular end points (CONVINCE) trial. JAMA 2003 Apr 23-30;289(16): 2073-2082.

13. Dalhof B, Sever PS, Poulter NR, Wedel H, Beevers DG, Caulfield M, Collins R, KjeldsenSE, Kristinsson A, McInnes GT, et al. Prevention of cardiovascular events with an antihypertensive regimen of amlodipine adding perindopril as required versus atenolol adding bendroflumethiazide as required in the Anglo-Scandinavian Cardiac Outcomes trial-Blood Pressure Lowering Arm (ASCOT-BPLA). Lancet 2005 Sep 10-16;366(9489):895-906.

14. William B, Lacy PS, Thom SM, Cruickshank K, Stanton A, Collier D, Hughes AD, Thurston H, O'Rourke M, CAFE Investigators, et al. Differential impact of blood pressure - lowering drugs on central aortic pressure and clinical outcomes: principal results of the conduit artery function evaluation (CAFÉ) study. Circulation 2006 Mar 7;113(9):1213-1225.

15. Messereli FH, Grossman E, Glodbourt U. Are Betablockers efficacious as first line therapy for hypertension in the elderly? JAMA 1998 Jun 17;279(23):1903-1907.

16. Staessen JA, Wang JG, Thijs L. Cardiovascular protection and blood pressure reduction: a meta-analysis. Lancet 2001 Oct;358(9290):1305-1315.

17. Lindholm LH, Carlberg B. Samuelsson O. Atenolol in hypertension: is it a wise choice? Lancet 2004 Nov 6-12;364(9446): 1684-1689.

18. Law MR, Morris JK, Wald DS. Use of blood pressure-lowering drugs in the prevention of cardiovascular disease: metaanalysis of randomized trials in the context of expectations from prospective epidemiological studies. BMJ 2009 May 19;338:1665-1684.

19. Kuyper LM, Khan NA. Atenolol vs nonatenolol beta-blockers for the treatment of hypertension: a meta-analysis. Can J Cardiol 2014 May;30 (Suppl 5):S47-53.

20. Khan N, McAlister FA. Re-examining the efficacy of betablockers for the treatment of hypertension: a meta-analysis [erratum in 2007;176:976]. CMAJ 2006 Jun 6;174(12):1737-1742.

21. Chobanian AV, Bakris GI, Black HR, Cushman WC, Green LA, Izzo JL Jr, Jones DW, Materson BJ, Oparil S, Wright JT Jr, et al. Seventh report of the Joint National Committee on Prevention, Detection, Evaluation and Treatment of High Blood Pressure. Hypertension 2003 Dec;42(6):1206-1252.

22. Rosendorff $\mathrm{C}$, Black HR, Cannon CP, Gersh BJ, Gore J, Izzo JL Jr, Kaplan NM, O'Connor CM, O'Gara PT, Oparil S, et al. Treatment of hypertension in the prevention and management of ischemic heart disease: a scientific statement from the American Heart Association Councils on Clinical Cardiology and Epidemiology and Prevention. Circulation 2007 May 29;115(21):2761-2788.

23. Beta-blocker Heart Attack Trial Research Group. A randomized trial of propranolol in patients with acute myocardial infarction. I. Mortality results. JAMA 1982 Mar 26;247(12):1707-1714.
24. Herlitz J, Karlson BW, Hjalmarson A. Ten year mortality in relation to original size of myocardial infarct: results from the Golthenburg metoprolol study. Br Heart J 1994 Mar;71(3): 238-241.

25. The Norwegian Multicenter Study Group. Timolol-induced reduction in mortality and re-infarction in patients surviving acute myocardial infarction. N Engl J Med 1981 Apr 2;304(14):801-807.

26. Dargie HJ. Effect of carvedilol on outcome after myocardial infarction in patients with left ventricular dysfunction: the CAPRICON randomized trial. Lancet 2001 May 5;357(9266):1385-1390.

27. Foody JM, Farrell MH, Krumholz HM. Beta-blocker therapy in heart failure. Scientific review. J Am Med Assoc 2002 Feb 20;287(7):883-889.

28. Teelink JR, Massie BM. The role of beta-blockers in preventing sudden death in heart failure. J Card Fail 2000 Jun;6(2 Suppl 1): 25-33.

29. Brophy JM, Joseph L, Rouleac JL. Beta-blockers in CHF: a Bayesian meta-analysis. Ann Intern Med 2001 Apr 3;134(7): 550-560.

30. Flather MD, Shibata MC, Coats AJ, Van Veldhuisen DJ, Parkhomenko A, Borbola J, Cohen-Solal A, Dumitrascu D, Ferrari R, Lechat $\mathrm{P}$, et al. Randomized trial to determine the effect of nebivolol on mortality and cardiovascular hospital admission in elderly patients with heart failure (SENIORS). Eur Heart J 2005 Feb;26(3):215-225.

31. FranklinSS,LarsonMG,KhanSA, WongND,LeipEP,KannelWB, Levy D. Does the relation of blood pressure to coronary heart disease risk change with aging? The Framingham Heart Study. Circulation 2001 Mar;103(9):1245-1249.

32. Silventoinen K, Magnasson PK, Neovius M, Sundström J, Batty GD, Tynelius P, Rasmussen F. Does obesity modify the effect of blood pressure on the risk of cardiovascular disease? Circulation 2008 Oct 14;118(16):1637-1642.

33. Medical Research Working Party. MRC trial of treatment of mild hypertension: principal results. BMJ 1985 Jul 13;291(6488): 97-104.

34. IPPPSH Collaborative Group. Cardiovascular risk and risk factors in a randomized trial of treatment - based on the beta-blocker oxprenolol. J Hypertens 1985 Aug;3(4):379-388.

35. Wikstrand J, Warnold T, Tuomilehto J, Olsson G, Barber HJ, Eliasson K, Elmfeldt D, Jastrup B, Karatzas NB, Leer J, et al. Metoprolol versus diuretics in hypertension. Morbidity results from MAPHY study. Hypertension 1991 Apr;17(4):579-588.

36. Messereli FH, Williams B, Ritz E. Essential hypertension. Lancet 2007 Aug 18;370(9587):591-603.

37. Cleophas TJ, Grabowsky I, Niemeyer MG, Mäkel WM, van der Wall EE, Nebivolol Follow-up Study Group. Paradoxic pressor effects of G-blockers in standing elderly patients with mild hypertension. Circulation 2002 Apr 9;105(14):1669-1671.

38. Messereli FH, Grossman E. Beta-blockers in hypertension: is carvedilol different? Am J Cardiol 2004 May 6;93(9A):7B-12B.

39. Pedersen ME, Cockroft JR. The vasodilatory beta-blockers. Curr Hypertens Rep 2007 Aug;9(4):269-277.

40. Agabiti Rosei E, RIzzoni D. Metabolic profile of nebivolol, a beta adrenoceptor antagonist with unique characteristics. Drugs 2007;67(8):1097-1107.

41. Laurent S, Boutouyrie P, Asmar R, Gautier I, Laloux B, Guize L, Ducimetiere $\mathrm{P}$, Benetos A. Aortic stiffness is an independent predictor of all-cause and cardiovascular mortality in hypertensive patients. Hypertension 2001 May;37(5):1236-1241. 
42. Van Bortel LM, Fici F, Mascagni F. Efficacy and tolerability of nebivolol compared with other antihypertensive drugs: a meta-analysis. Am J Cardiovasc Drugs 2008;8(1):35-44.

43. James PA, Oparil S, Carter BL, Cushman WC, DennisonHimmelfarb C, Handler J, Lackland DT, LeFevre ML, MacKenzie TD, Ogedegbe O, et al. Evidence-based guideline for the management of high blood pressure in adults. Report from the panel members appointed to the Eighth Joint National Committee (JNC 8). JAMA 2014 Feb 5;311(5):507-520.

44. Weber MA, Schiffrin EL, White WB, Mann S, Lindholm LH, Kenerson JG, Flack JM, Carter BL, Materson BJ, Ram CV, et al. Clinical practice guidelines for the management of hypertension in the community: a statement by the American Society of Hypertension and the International Society of Hypertension. J Hypertens 2014 Jan;32(1):3-15.

45. McManus RJ, Caulfield M, Williams B; National Institute for Health and Clinical Excellence. NICE hypertension guideline 2011: evidence based evolution. BMJ 2012 Jan 13; 344:e181.

46. Mancia G. Fagard R, Narkiewicz K, Redón J, Zanchetti A, Böhm M, Christiaens T, Cifkova R, De Backer G, Dominiczak A, et al. Task Force Members 2013 ESH/ESC. Guidelines for the management of arterial hypertension of the European Society of Hypertension (ESH) and of the European Society of Cardiology (ESC). J Hypertens 2013 Jul;31(7):1281-1357.

47. Daskalopoulou SS, Rabi DM, Zarnke KB, Dasgupta K, Nerenberg K, Cloutier L, Gelfer M, Lamarre-Cliche M, Milot A, Bolli P, et al. The 2015 Canadian Hypertension Education Program recommendations for blood pressure measurement, diagnosis, assessment of risk, prevention, and treatment of hypertension. Can J Cardiol 2015 May;31(5):549-568.

48. Dickey BF, WalkerJKL,Hanania NA, Bond RA. B-adrenoceptor inverse agonists in asthma. Curr Opin Pharmacol 2010 Jun;10(3):254-259. 